\title{
TANTANGAN DAN PELUANG IMPLEMENTASI PENDIDIKAN KARAKTER DALAM PRAKTEK KERJA LAPANGAN (PKL) DI ERA INDUSTRI 4.0
}

\author{
Lidia Karubaba ${ }^{1)}$; Regina Wutoy ${ }^{2)}$ \\ ${ }^{1}$ SMK Negeri 2 Manokwari Papua Barat; lidiamisiakarubaba@gmail.com \\ ${ }^{2}$ SMK Negeri 2 Manokwari Papua Barat; wutoyregina@gmail.com
}

\begin{abstract}
This study aims to determine (1) the influence of the industrial era 4.0 on the implementation of street vendors in SMK Negeri 2 Manokwari (2) the effect of strengthening character education on the implementation of street vendors in SMK Negeri 2 Manokwari. (3) Simultaneous influence of character education and industry era on the implementation of street vendors in SMK Negeri 2. Manokwari (4) The challenges of implementing street vendors in SMK Negeri 2 Manokwari. (5) Opportunities for implementing street vendors in SMK Negeri 2 Manokwari. The method used in this study is a quantitative method with quantitative analysis techniques. The results showed that: (1) There was no effect of the industrial era 4.0 on the implementation of street vendors in SMK Negeri 2 Manokwari. (2) There is an effect of strengthening character education on the implementation of street vendors in SMK Negeri 2 Manokwari. The effect of character education and industry era simultaneously on the implementation of street vendors in SMK Negeri 2. Manokwari. (3) The biggest challenge in implementing street vendors in SMK Negeri 2 Manokwari is family economic factors: the importance of strengthening the competency of students at apprenticeship, both in related OPDs, or in existing training bodies
\end{abstract}

Keywords: Field Work Practices; Industrial Era 4.0.

\begin{abstract}
ABSTRAK
Penelitian ini bertujuan untuk Mengetahui (1) Pengaruh era industri 4.0 terhadap pelaksanaan PKL di SMK Negeri 2 Manokwari (2) Pengaruh penguatan pendidikan karakter terhadap pelaksanaan PKL di SMK Negeri 2 Manokwari. (3) Pengaruh pendidikan karakter dan era industry 4.0 secara simultan terhdap pelaksanaan PKL di SMK Negeri 2. Manokwari.(4) Tantangan pelaksanaan PKL di SMK Negeri 2 Manokwari. (5) Peluang pelaksanaan PKL di SMK Negeri 2 Manokwari. Metode yang digunakan dalam penelitian ini adalah metode Kuantitatif dengan teknik analisis kuantitatif. Hasil penelitian menunjukkan bahwa : (1) Tidak ada Pengaruh era industri 4.0 terhadap pelaksanaan PKL di SMK Negeri 2 Manokwari. (2) Terdapat Pengaruh penguatan pendidikan karakter terhadap pelaksanaan PKL di SMK Negeri 2 Manokwari. Pengaruh pendidikan karakter dan era industry 4.0 secara simultan terhdap pelaksanaan PKL di SMK Negeri 2. Manokwari. (3) Tantangan terbesar dalam pelaksanaan PKL di SMK Negeri 2 Manokwari adalah faktor ekonomi keluarga :kepentingan pemantapan kompetensi peserta didik pada saat pemagangan, baik pada OPD-OPD terkait, ataupun pada badan diklat yang ada
\end{abstract}

Kata Kunci : Praktek Kerja Lapangan (PKL); Era Industri 4.0.

\section{PENDAHULUAN}

Membangun karakter anak adalah merupakan salah satu strategi yang dilakukan melalui proses pembudayaan di lingkungansekolah atau melalui budaya sekolah.Sesuai dengan desain induk pendidikan karakter yang dirancang maka strategi pengembangan pendidikan karakter dapat dilakukan melalui transformasi budaya sekolah dan habituasi melalui kegiatan pengembangan diri. Hal ini sejalan dengan pemikiran Berkowitz, yang dikutip oleh Elkind dan Sweet (2004) dalam Samani, dkk (2011) yang menyatakan bahwa: implementasi pendidikan 
karakter melalui transformasi budaya dan perikehidupan sekolah, dirasakan lebih efektif daripada mengubah kurikulum dengan menambahkan materi pendidikan karakter dalam muatan kurikulum.Dalam kaitan pengembangan budaya sekolah yang dilaksanakan dalam kaitan pengembangan diri, Kemendiknas menyarankan melalui 4 (empat) hal, yang meliputi : 1). Melalui kegiatan rutin, 2). Kegiatan spontan, 3). Keteladanan, dan 4). Melalui pengondisian.

Secara substantif karakter terdiri dari 3(tiga) nilai operatif, nilai-nilai dalam tindakan, atau unjuk perilaku yang satu sama lain saling berkaitan, antara lain: pengetahuan tentang moral (aspek kognitif); perasaan berdasarkan moral (aspek afektif); dan perilaku berlandaskan moral (aspek psikomotor). Karakter yang baik terdiri atas proses-proses yang meliputi, tahu mana yang baik, keinginan melakukan yang baik dan melakukan yang baik. Selain itu, karakter yang baik juga harus ditunjang oleh kebiasaan pikir, kebiasaan hati, dan kebiasaan tindakan. Dalam konteks realitas psikologis dan sosio-kultural dikategorikan menjadi : olah pikir, olah hati, olah raga dan kinestetik serta olah rasa dan karsa.

Karakter berkaitan dengan nilai-nilai, penalaran dan perilaku dari seseorang. Pendidikan karakter perlu didasarkan pada strategi yang tepat yaitucontoh/teladan, penjelasan, arahan/nasihat, lingkungan yang mendukung/etis, pengalaman, dan harapan yang tinggi. Perilaku tersebut kemudian terinternalisasi pada diri yang akan menjadi kebiasaan. Akhirnya semua itu dilakukan dengan harapan yang tinggi, bahwa perilaku tersebut mewujudkan hasil terbaik (Zamroni, 2011: 283). Pendidikan terstruktur seluruhnya menjadi tanggung jawab Kementerian Pendidikan Republik Indonesia (Depdiknas) dengan mewajibkan putra-putri Indonesia mengikuti wajib belajar sembilan tahun (6 tahun di SD, 3 tahun di SMP, 3 tahun di SMA/SMK), sebagaimana diatur dalam Pasal 1 butir 1 Undang-Undang Nomor 20 Tahun 2003 tentang Sistem Pendidikan Nasional untuk mempersiapkan generasi muda berkualitas. Guna menghasilkan lulusan yang kompetitif, maka dipandang perlu adanya perbaikan dan pengelolaan pendidikan, yang harus dilakukan oleh semua puhak yang bersinggungan dengan pendidikan itu sendiri. Perbaikan pendidikan yang diperlukan sekiranya harus berhubungan langsung dengan peserta didik, saranaprasarana, serta pendidik dan tenaga kependidikan untuk menjawab tuntukan perkembangan zaman.

Tuntutan perkembangan zaman serta teknologi yang digunakan saat ini terbilang semakin cepat dan berkembang pesat. Perubahan dan perkembangan teknologi dimulai sejak revolusi industri pertama yang terjadi di Inggris pada tahun 1780 sampai dengan perkembangan era industry ke 4.0 (http://kompasiana.com,2018), $\quad$ yang menghasilkan "pabrik cerdas" yang berstruktur modular, dimana sistim fiber-fisik mengawasi proses fisik, menciptakan salinan dunia fisik secara virtual dan membuat keputusan yang tidak terpusat, yang kesemuanya itu dilakukan dengan menggunakan teknologi computer dan pengembangan berbasis internet (https://id.m.wikipedia.org). 
Dampak utama revolusi industri keempat adalah pada bidang industri dan manufaktur, namun dampak pada bidang lain yang terpengaruh diantaranya terjadi pada bidang kesehatan, pendidikan, pemerintahan, ekonomi, dan masyarakat. Peningkatan produktivitas dalam bidang industri dan manufaktur dipandangn penting guna peningkatan produktifitas bagi perusahaan.

Revolusi industri 4.0 juga memberikan perubahan model kerja bagi industri dan manufaktur, yaitu dengan menggunakan teknologi robot yang sekarang ini telah digunakan oleh sebagian perusahaan. Robot diharapkan dapat mengurangi tenaga manusia dalam melakukan pekerjaan, dengan semua teknologi digital yang terkait (http://kompasiana.com,2018).

Pengaruh negatif maupun positif pada revolusi industri dapat memberikan gambaran bahwa persiapan dalam menghadapi revolusi industri 4.0 sudah mulai terjadi haruslah matang serta tepat, karena persiapan yang kurang akan membawa dampak negatif bagi diri sendiri maupun orang-orang disekitar kita. Pemerintah Indonesia juga mulai meresponi perkembangan revolusi industri 4.0 dengan diresmikannya

"Making Indonesia 4.0" oleh Presiden Joko Widodo pada tanggal 4 April 2018 yang bertujuan menjadikan Indonesia sebagai Negara kesepuluh(10) besar ekonomi dunia di tahun 2030 (https://m.detik.com). Adapun sektor manufaktur unggulan Indonesia adalah dalam bidang industri makanan dan minuman, tekstil dan pakaian, otomotif, bahan kimia, serta elektronika (https://media.com).Maka perkembangan pembelajaran di Indonesia juga dituntut untuk berbenah diri mengikuti perkembangan era industri 4.0 dengan beberapa petimbangan antaranya seperti pesatnya perkembangan teknologi, perubahan karakteristik pekerjaan, kebutuhan sumber daya manusia (SDM) unggul, meningkatkan daya saing nasional, serta pendidikan adalah persiapan untuk hidup (https://idntimes.com,2018).

Pembelajaran di era industri 4.0 dimana manusia dan teknologi diselaraskan untuk memungkinkan kemungkinan-kemungkinan baru. Pada jenjang SMK misalnya, model pembelajaran langsung melalui Praktik Kerja Lapangan (PKL) atau yang dulunya biasa disebut PRAKERIN (Praktek Kerja Industri) adalah bentuk pendidikan yang dilakukan secara sistematis dan sinkron antara program pendidikan di sekolah dengan program penguasaan keahlian yang diperoleh melalui kegiatan kerja secara langsung di dunia kerja untuk mencapai tingkat keahlian tertentu,melalui proses pembelajaran dan pelatihan secara praktis dalam bidang kompetensinya masing-masing. Hal ini dimaksudkan untuk memberikan pengalaman nyata bagi peserta didik tentang lingkungan kerja, etos dan budaya kerja yang belum diperoleh sepenuhnya di sekolah. Dari pengalaman Praktik Kerja Lapangan ini diharapkan peserta didik mendapatkan ketrampilan hidup yang akan berguna bagi perkembangan dirinya dimasa yang akan datang. Karakteristik proses pembelajaran disesuaikan dengan karakteristik program keahlian yang berada pada bidang keahlian yang dilakukan di sekolah/madrasah, di dunia 
kerja DU/DI atau gabungan dari keduanya. Pelaksanaan proses pembelajaran melibatkan DU/DI melalui model penyelenggaraan Praktik Kerja Lapangan.

Pembelajaran di dunia kerja DU/DI adalah program PKL yaitu kegiatan pembelajaran praktik untuk menerapan, memantapan, dan meningkatan kompetensi peserta didik.

Pola Penyelenggaraan PKL :

a). Pola harian (120-200 hari efektif).

b). Pola mingguan (24-40 minggu).

c). Pola bulanan (6-10 bulan).

Penguasaan kompetensi teknis dan kepribadian merupakan kunci sukses menuju harapan yang sangat dinanti-nantikan oleh siapapun,termasuk di kalangan Pendidikan di Provinsi Papua Barat khususnya di Kabupaten Manokwari. Data dari Lembaga Penjaminan Mutu Pendidikan(LPMP) Papua Barat, dalam tahun 2016/2017 telah dilaksanakan kegiatankegiatan yang melibatkan sekolahsekolah dari berbagai jenjang termasuk SMK se Papua Barat, yang telah menerapkan kurikulum 2013 dan siap menjadi pendamping bagi sekolah lainnya, dimana Penerapan kurikulum 2013 di

Papua Barat baru mencapai 35\% (https://kabarpapua.co). SMK Negeri 2 merupakan salah satu dari Sembilan SMK yang terdapat di kabupaten Manokwari, didirikan pada tahun 2000 dengan perkembangan sampai dengan tahun 2019, telah memiliki 7 jurusan dengan 11 program keahlian.Sebagai salah satu sekolah kejuruan yang menjalankan K.13di kabupaten Manokwari,sekolah ini juga telah dan selalu melaksanakan program wajib kejuruan pelaksanaan praktek kerja lapangan yang dilakukan setiap tahunnya dengan kerjasama dengan pihak DU/DI.

\section{METODE PENELITIAN}

Metode yang digunakan dalam penelitian ini adalah dengan menggunakan metode deskriptif kuantitatif. Menurut Sugiyono (2013), metode penelitian kuantitatif dapat diartikan sebagai metode penelitian yang berlandaskan pada filafat positivism, digunakan untuk meneliti pada populasi atau sampel tertentu, dengan teknik pengambilan sampel pada umumnya dilakukan secara random, pengumpulan data menggunakan instrument penelitian, dengan analisis data bersifat kuantitatif, dengan tujuan untuk menguji hipotesis yang telah ditetapkan.

Populasi dan Sampel dalam Penelitian ini adalah peserta didik SMKNegeri 2 Kabupaten Manokwari Papua Barat yang berjumlah 958 peserta didik, dengan besar sampel sekitar 165 peserta didik yang diambil dari kompetensi keahlian yang berbeda-beda, yang dihitung dengan menggunakan rumus penentuan sampel menurut Isaac dan Michael dalam Riduwan, (2012:50-51), dengan menggunakan teknik Proporsionate Stratified Random Sampling dimana anggota populasi tidak homogen dan penentuan sampel populasi yang berstrata harus proporsional (Mikha agus widiyanto, 2014. Adapun Instrument penelitian adalah alat ukur yang digunakan untuk mengukur fenomena alam maupun sosial yang diamati (Sugiyono, 2013),yakni dengan menggunakan pedoman kuisioner (daftar pertanyaan atau pernyataan) berbentuk angket berstruktur, Pedoman wawancara, Lembar ceklist, lembar observasi, test hasil belajar materi kejuruan berbentuk objektif/pilihan ganda,dan format hasil kerja 
PKL dari DU/DI (jurnal PKL). Analisis data adalah dengan menganalisis validitas dan reliabilitas data, normalitas, korelasi, dan regresi data penelitian guna memperoleh hasil yang maksimal (Arikunto, 2012), dan (Sugiyono, 2013).

\section{HASIL DAN PEMBAHASAN}

Hasil pengujian data dengan menggunakan SPSS 22.0 untuk menguji tingkat validitas dan reliabilitas instrument penelitian, maka diperoleh hasil bahwa pada variabel X1 dan Variabel X2 semua instrumennya dinyatakan valid dan reliabel. Sedangkan untuk variabel $\mathrm{Y}$, dari ke 41 item yang dinyatakan valid dan reliabel serta layak digunakan adalah 34 item sedangkan 7 item dinyatakan tidak valid dan tidak reliabel.

Uji normalitas data dengan menggunkan metode Kolmogorov-Smirnov di dapat hasil signifikasi dari uji normalitas sebesar 0,051 dimana hasil tersebut lebih besar dari taraf signifikansi 0,05 . Sehingga dapat disimpulkan bahwa uji normalitas pada penelitian ini terdistribusi normal.Hasil Uji Normalitas data dengan uji Kolmogorov Smirnov Test seperti yang terdapat pada tabel 1 - tabel 3 berikut ini:

\begin{tabular}{|c|c|c|}
\hline \multicolumn{3}{|c|}{$\begin{array}{c}\text { Tabel 1. Uji Normalitas dataOne-Sample } \\
\text { Kolmogorov-Smirnov Test }\end{array}$} \\
\hline & & $\begin{array}{r}\text { Unstandardized } \\
\text { Residual }\end{array}$ \\
\hline \multicolumn{2}{|l|}{$\mathrm{N}$} & 165 \\
\hline \multirow{2}{*}{$\begin{array}{l}\text { Normal } \\
\text { Parameters }\end{array}$} & Mean &, 0000000 \\
\hline & Std.Deviation & 12,28080308 \\
\hline \multirow{3}{*}{$\begin{array}{l}\text { Most Extreme } \\
\text { Differences }\end{array}$} & Absolute & ,069 \\
\hline & Positive &,- 045 \\
\hline & Negative &,- 069 \\
\hline \multicolumn{2}{|l|}{ Test Statistic } & ,069 \\
\hline \multicolumn{2}{|c|}{ Asymp. Sig. (2-tailed) } &, $051^{\mathrm{c}}$ \\
\hline \multicolumn{3}{|c|}{ a. Test distribution is Normal. } \\
\hline
\end{tabular}

Tabel 2. Uji korelasi Variabel X1 dan Y

\begin{tabular}{|c|c|c|c|c|c|}
\hline \multicolumn{6}{|c|}{ Coefficients $^{\mathrm{a}}$} \\
\hline \multirow[t]{2}{*}{ Model } & $\begin{array}{r}\text { Unstand } \\
\text { Coeffi }\end{array}$ & $\begin{array}{l}\text { Irdized } \\
\text { ients }\end{array}$ & $\begin{array}{l}\text { Standardized } \\
\text { Coefficients }\end{array}$ & $\mathrm{T}$ & Sig. \\
\hline & B & $\begin{array}{l}\text { Std. } \\
\text { Error }\end{array}$ & Beta & & \\
\hline $\begin{array}{l}1 \text { (Consta } \\
\text { nt) }\end{array}$ & 144.690 & 13.651 & & 10.599 & .000 \\
\hline $\mathrm{X} 1$ & 2.727 & $\begin{array}{r}2.15 \\
4\end{array}$ & -.099 & -1.266 . & .207 \\
\hline
\end{tabular}

Tabel 3. Uji Regresi dengan variabel $X$ terhadap variabel $Y$

\begin{tabular}{|c|c|c|c|}
\hline \multicolumn{4}{|c|}{ Correlations } \\
\hline & & $\mathrm{X} 1$ & $\mathrm{Y}$ \\
\hline \multirow[t]{3}{*}{$\mathrm{X} 1$} & Pearson Correlation & 1 & -.099 \\
\hline & Sig. (2-tailed) & & .207 \\
\hline & $\mathrm{N}$ & 165 & 165 \\
\hline \multirow[t]{3}{*}{$\mathrm{Y}$} & $\begin{array}{l}\text { Pearson } \\
\text { Correlation }\end{array}$ & -.099 & 1 \\
\hline & Sig. (2-tailed) & .207 & \\
\hline & $\mathrm{N}$ & 165 & 165 \\
\hline
\end{tabular}

Berdasarkan hasil analisis korelasi pada tabel 1 dan 2 hasil analisis regresi sederhana sedangkan pada tabel 3 menunjuhkan bahwa pelaksanaan $\mathrm{PKL} /$ pemagangan secara umum tidak ada hubungannya dengan perkembangan era industri 4.0 yang sementara sedang berlangsung dengan gencanya. Hal ini dapat Diketahui melalui hasil uji nilai korelasi dengan sig. untuk pengaruh $\mathrm{X} 1$ terhadap $\mathrm{Y}$ adalah sebesar 0,207>0,05 dan nilai $\mathrm{r}$ hitung $0,099<\mathrm{r}$ tabel 0,1528. Demikian juga dengan hasil uji regresi yang menunjukan hasil yang sama dimana diketahui nilai sig. untuk pengaruh X1 terhadap Y adalah sebesar 0,214 > 0,05 dan nilai t hitung $-1,248<1,654$ sehingga dapat disimpulkan bahwa tidak terdapat pengaruh antara perkembangan era industri 4.0 
dengan pelaksanaan PKL/pemagangan yang dilakukan oleh peserta didik di SMK Negeri 2 Manokwari.

Pada umumnya pelaksanaan PKL yang dilakukan oleh peserta didik di SMK Negeri 2 Manokwari belum masuk pada era industri 4.0.

Menurut Regina Wutoy (2015), yang menyatakan bahwa pembelajaran yang dilakukan di sekolah hendaknya disesuaikn dengan materi yang ada, sehinga dapat mencapai hasil yang maksimal. Pelaksanaan pembelajaran di sekolah juga hendaknya disesuaikan dengan kebutuhan dan ketersediaan pekerjaan di dunia usaha dan dunia industri, karena perkembangan DU/DI di setiap daerah berbeda-beda.

Hal ini dapat dilihat dengan adanya industri industri kecil ataupun besar yang ada di wilayah Manokwari yang belum seluruhnya bekerja dengan sistem digitalisasi karena ratarata pelaksanaan pekerjaan yang dilakukan oleh DU/DI tersebut masih banyak yang dikategorikan dilakukan dengan sistem yang standar. Kalaupun terdapat perusahaan perusahaan besar yang beroperasi di wilayah Manokwari dan sekitarnya yang sudah menerapkan system digitalisasi dalam proses maupun pengolahannya seperti pabrik semen Conch Manokwari, LNG Tangguh Babo, ataupun yang beroperasi di wilayah Papua seperti PT. Freeport Tembagapura. Faktor semangat, disiplin, kerja keras, dan sikap positif lainnya terbilang masih mendominasi dalam pelaksanaan PKL/pemagangan di era 4.0. oleh sebab itu pendidikan juga dituntut untuk berbenah diri guna mampu menjawab perkembangan era industri yang terus melaju pesat, agar dapat menghasilkan tenaga-tenaga kerja yang berkompeten dan mampu bersaing bukan hanya di kancah nasional tetapi juga bersaing secara global. Untuk melengkapi kompetensi peserta didik guna menjawab tantangan era industri 4.0 maka dibutuhkan kerjasama semua pihak, baik pihak swasta (DU/DI) ataupun juga pihak pemerintah daerah agar perkembangan industri yang ada di wilayah Manokwari dan sekitarnya termasuk di tanah Papua secara umum dapat bersaing untuk mempertajam sektor manufaktur unggulan Indonesia dalam bidang industri seperti yang telah diresmikan pada tanggal 4 April 2018. Uji korelasi dan uji regresi variabel X2 terhadap variabel Y ditunjukan pada Tabel 4 dan 5 sebagai berikut:

Tabel 4.Uji korelasi Variabel X2 dan Y

\begin{tabular}{|l|l|r|r|}
\hline \multicolumn{3}{|c|}{ Correlations } \\
\hline X2 & Pearson Correlation & X2 & \multicolumn{1}{|c|}{ Y } \\
& Sig. (2-tailed) & & $.301^{* *}$ \\
\hline & N & 165 & .000 \\
\hline Y & Pearson Correlation & $.301^{* *}$ & 165 \\
\hline & Sig. (2-tailed) & .000 & 1 \\
\hline & N & 165 & 165 \\
\hline & **. Correlation is significant at the 0.01 \\
& \\
& level (2-tailed). \\
\hline
\end{tabular}

Tabel 5 uji regresi dengan variabel X2 terhadap variabel $\mathbf{Y}$

\begin{tabular}{|c|c|c|c|c|c|}
\hline \multicolumn{6}{|c|}{ Coefficients ${ }^{\mathrm{a}}$} \\
\hline \multirow[t]{2}{*}{ Model } & \multicolumn{2}{|c|}{$\begin{array}{l}\text { Unstandardized } \\
\text { Coefficients }\end{array}$} & \multirow{2}{*}{\begin{tabular}{|c} 
Standardized \\
Coefficients \\
Beta
\end{tabular}} & \multirow[t]{2}{*}{$\mathrm{T}$} & \multirow[t]{2}{*}{ Sig. } \\
\hline & B & $\begin{array}{l}\text { Std. } \\
\text { Error }\end{array}$ & & & \\
\hline 1 (Constant) & 92.289 & 8.767 & & 10.527 & .000 \\
\hline $\mathrm{X} 2$ & .324 & .080 & .301 & 4.035 & .000 \\
\hline
\end{tabular}


Berdasarkan hasil analisis korelasi pada tabel 4 dan hasil analisis regresi sederhana pada tabel 5 menunjuhkan bahwa pelaksanaan PKL/pemagangan secara umum berhubungan dengan penguatan pendidikan karakter yang hasur dimiliki oleh peserta didik sebagai bekal ketika akan terjun ke dunia kerja. Hal ini dapat dilihat dimana nilai sig. untuk pengaruh $\mathrm{X} 2$ terhadap Y adalah sebesar $0,000<0,05$ dan nilai $\mathrm{r}$ hitung $0,301>0,1528$ sehingga dapat disimpulkan bahwa terdapat hubungan antara penguatan pendidikan karakter dengan pelaksanaan $\mathrm{PKL} /$ pemagangan peserta didik. Demikian juga dengan hasil uji regresi yang menunjukan hasil yang sama dimana diketahui nilai sig. untuk pengaruh $\mathrm{X} 2$ terhadap $\mathrm{Y}$ adalah sebesar $0,000<0,05$ dan nilai t hitung 4,018 > 1,654 sehingga dapat disimpulkan bahwa terdapat pengaruh antara penguatan pendidikan karakter dengan pelaksanaan PKL/pemagangan peserta didik.

$$
\text { Pada prinsipnya pelaksanaan }
$$

PKL/pemagangan selalu mengacu pada (Peraturan Pemerintah Nomor 29 Tahun 1990 Pasal 2 Ayat 1), dimana tujuan pendidikan menengah kejuruan yakni membentuk peserta didik yang berkarakter keimanan dan ketaqwaan, berakhlat mulia, sehat, berilmu, cakap, kreatif, mandiri, demokratis, bertanggung jawab, berwawasan, menghargai, peduli, mampu memilih karier, ulet dan gigih. Kesemua sikap/karakter ini adalah landasan/pijakan utama bagi peserta didik untuk berkarya serta mampu berkompetensi di bidangnya masing-masing. Dengan bekal pendidikan karakter yang optimal, maka diharapakan peserta didik mapu menjadi manusia produktif yang mandiri dan berkompeten dalam program keahliannya. Sesuai (Peraturan Pemerintah Nomor 87 Tahun 2017), maka sudah menjadi tugas bersama untuk memperkuat karakter peserta didik dengan menitik beratka pada olah hati, olah rasa, olah karsa, dan olah raga yang mana hal ini juga harussejalan dengan gerakan nasional revolusi mental yang lebih dikhususkan pada perubahan pola berpikir, bersikap, dan bertindak menjadi lebih baik. Oleh sebab itu perlunya pembentukan karakter dengan lebih menekankan pada nilai-nilai utama pendidikan karakter antara lain adalah religious, intergritas, mandiri, gotong-royong, dan nasionalis. Dalam kelima poin ini terdapat sub-sub nilai karakter yang sangat penting yang menjadi titik penentu keberhasilan pelaksanaan PKL/pemagangan yang dilakukan oleh peserta didik di DU/DI (Akhmad, Arifin 2012). Aplikasi dari nilai-nilai karakter diharapkan dapat menjadi salah satu bagian terpenting dalam pembentukan kepribadian peserta didik yang tangguh serta mampu bersaing di era industri modern. Hal in dipandang sangat penting karena kemajuan era industri 4.0 yang sesungghnya akan menggantikan peran manusia dalam prosesproses yang mendasar yang dikerjakan di industri- industri maju. Akhirnya dibutuhkan tenaga kerja yang berkompeten serta memiliki karakter tangguh agar dapat bersaing dalam perkembangan industri yang serba modern di tahun-tahun mendatang (Yahya, M., 2018). Uji regresi berganda ditunjukkan pada tabel 6 sebagai berikut: 
Tabel 6 Uji Regresi Berganda

\begin{tabular}{|c|c|c|c|c|c|c|}
\hline \multicolumn{7}{|c|}{ ANOVA $^{a}$} \\
\hline \multicolumn{2}{|c|}{ Model } & $\begin{array}{l}\text { Sum of } \\
\text { Squares }\end{array}$ & & $\begin{array}{l}\text { Mean } \\
\text { Square }\end{array}$ & $\mathrm{F}$ & Sig. \\
\hline \multirow[t]{3}{*}{1} & $\begin{array}{l}\text { Regres } \\
\text { sion }\end{array}$ & 2732.737 & 2 & $\begin{array}{r}1366.3 \\
68\end{array}$ & 8.949 & $.000^{\mathrm{b}}$ \\
\hline & $\begin{array}{l}\text { Residu } \\
\text { al }\end{array}$ & 24734.172 & 162 & 152.680 & & \\
\hline & Total & 27466.909 & 164 & & & \\
\hline & $\begin{array}{l}\text { a. De } \\
\text { b. Pre }\end{array}$ & $\begin{array}{l}\text { dent Vari } \\
\text { tors: (Co }\end{array}$ & $\begin{array}{l}\text { ble: } \\
\text { stant }\end{array}$ & Y X2, X & & \\
\hline
\end{tabular}

Hasil analisis uji regresi berganda seperti yang terdapat pada tabel 6 menunjuhkan bahwa pelaksanaan $\mathrm{PKL} /$ pemagangan secara umum berhubungan dengan era industri 4.0 serta penguatan pendidikan karakter yang harus dimiliki oleh peserta didik sebagai bekal ketika akan terjun ke dunia kerja. Hal ini dapat dilihat dimana nilai sig. untuk pengaruh $\mathrm{X} 1$ dan $\mathrm{X} 2$ secara simultan terhadap $\mathrm{Y}$ adalah sebesar $0,000<0,05$ dan nilai $\mathrm{F}$ hitung 8,949 $>\mathrm{F}$ tabel 3,05 sehingga dapat disimpulkan bahwa terdapat pengaruh $\mathrm{X} 1$ dan $\mathrm{X} 2$ secara simultan terhadap Y. Pelaksanaan PKL/pemagangan di SMK Negeri 2 Manokwari Papua Barat di tahun 2019 sudah dilakukan sesuai dengan aturan yang berlaku, kalaupun sebagian besar aktivitas yang dilakukan di DU/DI belum sepenuhnya berhubungan dengan akses internet. Rata-rata DU/DI yang sudah menggunakan akses teknologi digitalisasi/internet antara lain seperti Industri-indistri rumahan, perhotelan, perkantoran, dinas-dinas dan instansi-instansi pemerintah yang juga menggunakan internet sebagai bagian terpenting dari pekerjaannya.

Manurut Muhammad Yahya (2018), Industri 4.0 membutuhkan tenaga kerja yang memiliki keterampilan dalam literasi digital, literasi teknologi, dan literasi manusia. Pendidikan kejuruan harus mampu membekali lulusan dengan ketiga literasi tersebut melalui revitalisasi chronosystem yang meliputi sistem pembelajaran, satuan pendidikan, peserta didik, dan pendidik serta tenaga kependidikan. Dengan mengutip pendapat tersebut di atas tentang sistem pembelajaran, satuan pendidikan, peserta didik, dan pendidik serta tenaga kependidikan, maka diharapkan penguatan pedidikan karakter yang dilengkapi dengan penguasaan teknologi yang mendukung kinerja peserta didik dibidangnya akan sangat membantu peserta didik dalam memantapkan kompetensi untuk dapat dijadikan model kerja saat nantinya diterjunkan dalam dunia kerja. Adapun tantangan terbesar dalam pelaksanaan PKL adalah faktor ekonomi keluarga peserta didik.Sedangkan peluang antara lain dengan cara membuka kerjasama dengan pihak DU/DI,OPD terkait, P4TK, serta BLK

Jayapura. Prestasi-prestasi yang telah diperoleh antara lain memperoleh prestasi baik dalam lomba-lomba LKS tingkat provinsi dan tingkat nasional serta Asian Skiil, serta penghargaan dari DU/DI tempat PKL berlangsung

\section{SIMPULAN DAN SARAN SIMPULAN}

Tidak terdapat pengaruh antara era industri 4.0 dengan pelaksanaan PKL/pemagangan peserta didik kelas XI SMKN 2 Manokwari sedangkan untuk Penguatan pendidikan karakter dengan pelaksanaan PKL pemagangan dan secara simultan antaraera industri 4.0 dan penguatan pendidkan karakter terhadap Pelaksanaan 
PKL/pemagangan. Pengaruh tantangan terbesar dalam pelaksanaan PKL di SMK Negeri 2 Manokwari setiap tahunnya adalah masalah ekonomi keluarga.

\section{SARAN}

Pelaksanaan PKL agar ditingkatkan pemagangan ke luar daerah seperti membuka kerjasama dengan beberapa P4TK diluar daerah seperti P4TK Bandung, P4TK Malang, Balai Pelatihan/BLK Jayapura, OPD-OPD terkait, Industri-Industri besar yang tersebar di wilayah Papua dan Papua Barat.

\section{DAFTAR PUSTAKA}

Akhmad, Arifin, 2012, Karakter dan Budaya Sekolah (https://ulilalbabjong.wordpress.com), di unduh tanggal 12 Februari 2019.

Arikunto, S., 2012, Uji Validitas dan Reliabilitas Data Penelitian.

https://m.detik.com, diunduh pada tanggal 27 Februari 2019

https://media.com, diunduh pada tanggal 29 Februari 2019.

https://idntimes.com, 2018, diunduh pada tanggal 27 Februari 2019

https://kabarpapua.com, diunduh pada tanggal 27 Februari 2019

http://kompasiana.com, diunduh pada tanggal 29 Februari 2019,

https://id.m.wikipedia.org., diunduh pada tanggal 29 Februari 2019,

Muh, Yahya, 2018,Era industri 4.0: tantangan dan peluang perkembangan pendidikan kejuruan Indonesia.

Peraturan Pemerintah,Nomor 29 Tahun 1990 pasal 2 ayat (1) tentang tujuan praktekkerjaindustri,

(http://pklalittihad.blogspot.com/praktek-

kerjaindustri.html), Diunduh tanggal 12

Februari 2019.

Peraturan Pemerintah,Nomor 87 Tahun 2017

Tentang Penguatan Pendidikan Karakter.

Riduwan, 2012, Metode dan Teknik

Penyusunan Proposal Penelitian,

Bandung, Alfabeta.

Samani,Muchlas dan Hariyanto, 2011, Konsep dan Model Pendidikan Karakter, Bandung, PT Remaja Rosda Karya.

Sisdiknas, (2003),UU Nomor 20 Tahun 2003 tentang SMK merupakan salah satu bentukPendidikanformal,(http://www.ser dosdiktis.net/serdos/file/dokumen/UUNo 20.pdf), Diunduh tanggal 12 Februari 2019.

Sugiyono, (2013), Metode Penelitian Pendidikan: Pendekatan Kuantitatif, Kualitatif dan R\&D,Bandung, Alfabeta.

Zamroni, 2011, Dinamika Peningkatan Mutu, Yogyakarta, Gavin Kalam Utama.

Widiyanto, A.M, 2014, Teknik Pengambilan Sampel.

Wutoy, A.R, 2015, Perbedaan Model Pembelajaran Kooperatif Tipe Student Teams Achievements Divisions (STAD) dengan tipe Number Head Togethers (NHT) terhadap motivasi dan hasl belajar kimia peserta didik kelas XII SMK Negeri 2 Manokwari, Journal Ilmu Pendidikan Volume 3 NO.1. 